\title{
Foreshock and aftershock sequences of the Cremasta earthquake and their relation to the waterloading of the Cremasta artificial lake
}

\author{
P. Comninakis - J. Drakopotlos - G. Moumoulidis - B. Papazachos
}

Ricevuto il 27 settembre 1967

SUmMary. -.. Investigation of the time and magnitude distribution of the fore- and aftershocks of the Cremasta lake earthquake which occurred on February 5, 1966 is made. The deformation characteristics and spatial distribution of these shocks is also studied. Strong evidence is pre. sented that the foreshocks and the main shock have been triggered by the waterloading of the Cremasta artificial lake.

Riassunto. - $\grave{E}$ stato fatto uno studio sulla distribuzione dei tempi, della magnitudo, sulle caratteristiche della deformaziono e la distribuzione nello spazio delle scosse che hamno preceduto e seguito il terremoto del 5 Febbraio 1966, avvenuto nel Iago di Cremasta.

Viene messo in grande evidenza il fatto che sia le scosse premonitrici che la scossa principale sono state provocate dal progressivo invaso (e quindi dal progressivo aumento della pressione idrica nel bacino) del Lago artifi. ciale di Cremasta.

\section{INTRODUCTION.}

On January 21, 1966 the Electric Power Corporation of Greece sent a letter to the Seismological Institute of the National Observatory of Athens by which we were informed that a large number of very small shocks was felt by the inhabitans of the villages situated close to the Cremasta Lake $\operatorname{dam}\left(38.9^{\circ} \mathrm{N}, 21.5^{\circ} \mathrm{E}\right)$. According to this letter small shocks were continuously felt since the beginning of December 1965 , but between 16 th and 19 th of January the engineers, who worked at the electric station of Cremasta, felt seven sudden shocks (of short period) with intensities between IV and V on the Mercalli intensity 
scale. These shocks were preceded or followed by earth sounds giving the impression of "abrupt striking at depth".

People of nearby villages were threatened by the shocks, which were attributer by them to the water reservoir of the Cremasta artificial lake. The Electric Power Corporation asked our Institute to undertake the investigation of existence of any relation between the autquake activity and water load. Unfortunately no portable seismographs were available at that time and no quick installation of other heavy instruments was possible.

The filling of the lake started on July 21, 1965. Some shocks were felt in the vicinity of the lake since $A$ ugust, according to positive information of $\mathrm{N}$. Delibasis of our Institute who visited the area, but in December the earthquake frequency starterl increasing exponentially untill February 5, 1966 when the strong earthquake of magnitude $M=6.3$ occurred at $02^{\mathrm{n}} 01^{\mathrm{m}} 43^{\mathrm{s}}$. The epicenter of this shock $\left(39.1^{\circ} \mathrm{N}, 21.6^{\circ} \mathrm{E}\right)$ is very close to the northern coast of the lake, about $25 \mathrm{~km}$ north of the dam. The earthquake was followed by an aftershock sequence which continued through the remainder of 1966 .

From August till December 1965 the Seismological Institute installed four new stations in the region of Greece of three components each, with the financial support of the United States $A$ ir Force Office of Scientific Research. The seismographs are of short period $\left(T_{s}=\right.$ $0.5 \mathrm{sec}, T g=1.0 \mathrm{sec}$ ), Sprengnether type. One of these stations was installerl at Valsamata $\left(38.2^{\circ} \mathrm{N}, 20.6^{\circ} \mathrm{E}\right)$ on Kephallenia island on August 29, 1965 at a distance of about $115 \mathrm{~km}$ from the Cremasta lake dam. The magnification of the vertical component of this station is about 50,000 at $T=0.5$ sec. About 740 foreshocks and 2580 aftershocks of $M_{L}$ magnitude between 2.0 and 5.6 have been recorderl. $A$ large number of shocks of this sequence has been recorded by the four new stations of the network as well as by the central station in Athens.

It was thought that a detailed study of this earthquake sequence would probably lead to interesting results regarding the relation between the waterloarling in the Cremasta lake and the earthquake occurrence and contribute to a better understanding of the laws of energy release by foreshocks and aftershocks. We shall present evidence that the reservoir loarling may have influencer the generation of the foreshocks as well as the main shock. This is a unique phenomenon because it is the first observer case in which an earthquake of such a large magniturle is believed to have been triggered by an artificial lake. 
Cases which evidence that earthquake occurrence is influenced bs reservoirs or other irregular crustal loading have been reported by some scientists.

D.S. Carder [1] brought forward evidence that reservoir loading affects local seismic activity in Boulder dam area. In a letter sent to us on May 13, 1966 Dr. Carder stated that since his first work he had made new observations in the same area and collected data, not published yet, which supported his first conclusions. Guha, Ram and Rao ( $\left.{ }^{2}\right)$ presented evidence of a correlation between the frequency of small local earthquakes and variations in flood intensity of streams. L. D. McGinnis $\left({ }^{3}\right)$ observed that the earthquake frequency increases in the Mississipi valley with the rate of water in the river. $T$. Matuzawa $\left(^{4}\right)$ describes relationship observed between the low ocean tides and earthquake swarms in the Bay of Sagami. E. Berg $\left(^{5}\right)$ made observations which indicate that the March 28 Alaskan earthquake of 1964 and its aftershocks have possibly been triggered by low ocean loads. D. MI. Evans ( $\left.{ }^{6}\right)$ presented strong evidence of a correlation between injected waste water in a deep well at the Rocks Mountain Arsenal, near Denver, and the frequency of earthquakes which occurred in that region between March 1962 and September 1965. No shock was observed at that region from 1882 till 1962. P. Caloi called engineers attention to these problems since $1951\left(^{7}\right)$, and afterwards by a study of $1965\left(^{8}\right)$; he, moreover, examined the probable reasons of a part Vajont reservoir destruction on October 9, 1963, on the basis of georlynamic investigation in the gorge of Vajont $\left({ }^{9}\right)$. He attributes the destruction partly to the disturbance of the tectonic equilibrium due to the reservoir. A. Galanopoulos ( ${ }^{10}$ ) observed that a swarm of earthquakes of magnitude between 1 and 3 had occurred in Spring 1953 close to the Marathon lake near Athens during a seas mal maximum of the water loading and presented the first evidence of a correlation between waterload of the Cremasta Lake and seismic activity. There is also some information $\left({ }^{5},{ }^{10}\right)$, that the reservoir filling causes an increase in the seismic activity near the artificial lakes Kariba Rodesia) and Koyna (India).

\section{Proceduke.}

An approximate determination of epicenters has been made for a large number of foreshocks and aftershocks. However, an accurate determination of epicenters (with an error $\pm 0.1^{\circ}$ ) has been made 
only for earthquakes with $M_{L} \geqslant 3.4$. $P n$ of the most of these shocks has been recorded clearly at three or more stations. To determine epicenters the method of Ben Ieneham and Bath ("1) has been used. $\Lambda$ program based on this method has been written for an IBMI 1620 computer. This method is applied to the routine work of determining epicenters for the bulletin of our Institute and has been proved well conditioned for epicenters in most places in the region of Gre: ce, when $P n$ is clearly recorded at three or more stations. In some cases in which this method could not be applied, other graphical methods were used for epicenter determination. No attempt has been made to determine focal depths of the shocks of the sequence, except for the main shock, because no reliable method could have been applied for this purpose, since no station was very close to the epicentral region. However, it was observed that $P n$ amplitudes were small in comparison with $P g$. That was particularly obvious in foreshocks. This is the first instrumental evidence that aftershock foci were not in the lower part of the crust and foreshocks were very shallow. The fact that foreshocks were felt as quakes of very short duration also indicates that they were very shallow. We shall present later more evidence which support the conclusion.

To calculate the magnitude $M^{\prime}{ }_{L}$ of each shock of the sequence for which an amplitude $A^{\prime}$ was measured at the station of Valsamata the following relation was used:

$$
M^{\prime}{ }_{L}=\log A^{\prime}+\bar{M}_{L}-\frac{\sum_{i=1}^{n} \log A_{i}}{n}
$$

where $\bar{M}_{L}$ is the mean value of the magnitudes of all shocks of the sequence recorded by the Wood- $\Lambda$ nderson seismograph $(T=0.8 \mathrm{sec}$, $V=2800)$ in Athens. $A$ and $n$ are the amplitude at Valsamata and the number of these shocks respectively. This method is reliable only when the epicentral distance of the shocks does not vary largely. To be sure that no large errors are introduced in determining magnitudes of the small shocks, the epicentral distances from the Valsamata station of all shocks have been determined by using the arrival times of several phases and travel time curves. The distances varied from about $110 \mathrm{~km}$ to $150 \mathrm{~km}$ but the epicentral distances of the large majority of shocks were close to $120 \mathrm{~km}$. Some errors, of course, have been introduced, but the conclusions of this study are not affected by such errors. The origin times, coordinates of epicenters and 
Table I - Foreshocks aNd AFTershocks of $M_{L} \geqslant 3.4$ of tile Cremasta Lake Earthquake.

\begin{tabular}{|c|c|c|c|c|c|c|c|}
\hline$N^{\circ}$ & & ate & & $\varphi$ & $\lambda$ & Origin Time & $\underset{M_{L}}{\text { Magnitude }}$ \\
\hline 1 & Sept. & II & 1965 & $39^{1} / 4^{\circ}$ & $22.0^{\circ}$ & $04: 49: 05$ & 3.7 \\
\hline 2 & Dec. & 31 & $"$ & $39.3^{\circ}$ & $20.9^{\circ}$ & $22: 43: 19$ & 4.1 \\
\hline 3 & Jan. & 6 & 1966 & $39.3^{\circ}$ & $21.3^{\circ}$ & $02: 01: 51$ & 3.4 \\
\hline 4 & $"$ & 16 & $"$ & $39.3^{\circ}$ & $21.0^{\circ}$ & $20: 03: 33$ & - \\
\hline 5 & $"$ & 19 & $"$ & $38.8^{\circ}$ & $21.4^{\circ}$ & $07: 26: 53$ & 3.9 \\
\hline b & $"$ & 22 & $"$ & $39.2^{\circ}$ & $21.5^{\circ}$ & $05: 01: 36$ & 3.8 \\
\hline 7 & $"$ & 26 & $"$ & $39.2^{\circ}$ & $21.0^{\circ}$ & $13: 30: 20$ & 4.2 \\
\hline 8 & $"$ & $n$ & " & $39.1^{0}$ & $21.4^{0}$ & $17: 34: 00$ & 3.4 \\
\hline 9 & $"$ & 28 & $"$ & $38.9^{\circ}$ & $21.3^{\circ}$ & $19: 30: 27$ & 3.5 \\
\hline 10 & $"$ & 30 & $"$ & $39.1^{\circ}$ & $21.4^{\circ}$ & $03: 01: 48$ & 3.8 \\
\hline 11 & $"$ & $"$ & $"$ & $39.0^{\circ}$ & $21.5^{\circ}$ & $05: 50: 09$ & 3.6 \\
\hline 12 & $"$ & $"$ & $"$ & $39.0^{\circ}$ & $21.5^{\circ}$ & $06: 46: 54$ & 3.8 \\
\hline 13 & $"$ & 31 & " & $39.1^{0}$ & $21.5^{\circ}$ & $04: 30: 50$ & 3.8 \\
\hline 14 & $"$ & $"$ & $"$ & $39.2^{\circ}$ & $21.1^{\circ}$ & $09: 54: 54$ & 4.0 \\
\hline 15 & $"$ & $"$ & $"$ & $39.2^{\circ}$ & $21.5^{\circ}$ & $10: 53: 22$ & 3.6 \\
\hline 16 & Feb. & 1 & $"$ & $\cdots$ & 一 & $05: 00$ & 3.4 \\
\hline 17 & $"$ & $"$ & $"$ & 一 & - & $06: 51$ & 3.5 \\
\hline 18 & $"$ & $"$ & " & $39.2^{\circ}$ & $21.5^{\circ}$ & $10: 03: 56$ & 3.6 \\
\hline 19 & $"$ & 2 & ") & $39.2^{\circ}$ & $21.7^{\circ}$ & $23: 51: 31$ & 3.6 \\
\hline 20 & $n$ & 4 & $"$ & $39^{1} / 4^{0}$ & $21^{1 / 4} 4^{0}$ & $17: 55: 45$ & 3.6 \\
\hline MS & $n$ & 5 & $n$ & $39.1^{\circ}$ & $21.6^{\circ}$ & $02: 01: 43$ & 5.9 \\
\hline 1 & $"$ & $"$ & $"$ & $39.2^{\circ}$ & $21.5^{\circ}$ & $02: 11: 02$ & 4.6 \\
\hline 2 & $"$ & $"$ & $"$ & $39.2^{\circ}$ & $21.7^{\circ}$ & $02: 29: 53$ & 3.6 \\
\hline 3 & $"$ & $"$ & $"$ & $39.1^{\circ}$ & $21.7^{\circ}$ & $02: 56: 16$ & 3.8 \\
\hline 4 & $"$ & $"$ & $"$ & $39.2^{\circ}$ & $21.7^{\circ}$ & $02: 57: 58$ & 4.9 \\
\hline 5 & $"$ & $"$ & $"$ & - & - & $04: 39$ & 3.5 \\
\hline 6 & $n$ & ") & $"$ & $39.3^{\circ}$ & $21.6^{\circ}$ & $04: 56: 29$ & 3.5 \\
\hline 7 & $"$ & $"$ & $"$ & $39.4^{\circ}$ & $21.6^{\circ}$ & $09: 28: 27$ & 3.6 \\
\hline 8 & $"$ & $"$ & $"$ & $39.2^{\circ}$ & $21.6^{\circ}$ & $09: 47: 57$ & 3.7 \\
\hline
\end{tabular}


44 P. COMNINAKIS - J. DRAKOPOULOS - G. MOUMOULIDIS - B. PAPAZACHOS

Continued

\begin{tabular}{|c|c|c|c|c|c|c|c|}
\hline No & & ate & & $p$ & $\lambda$ & Original Time & $\underset{M_{L}}{\operatorname{Marnit} n \mathrm{de}}$ \\
\hline 9 & IPets. & 5 & 1966 & $39.2^{\circ}$ & $21.7^{\circ}$ & $10: 39: 56$ & 3.6 \\
\hline 10 & $"$ & $n$ & $n$ & $39 \cdot 1^{0}$ & $21.6^{\circ}$ & $10: 52: 42$ & 3.5 \\
\hline 11 & $n$ & $"$ & $"$ & $39.6^{\circ}$ & $21.5^{0}$ & $12: 38: 35$ & 3.7 \\
\hline 12 & $n$ & $"$ & $"$ & $39.3^{\circ}$ & 21.70 & $13: 11: 58$ & 3.5 \\
\hline 13 & $"$ & $"$ & $"$ & $39.3^{\circ}$ & $21.7^{0}$ & $18: 29: 45$ & 3.4 \\
\hline 14 & $”$ & $"$ & $"$ & $39.4^{\circ}$ & $21.7^{\circ}$ & $19: 00: 22$ & 3.7 \\
\hline 15 & $"$ & 6 & $”$ & $39.1^{\circ}$ & $21.7^{\circ}$ & $00: 35: 04$ & 3.5 \\
\hline 16 & $"$ & $"$ & ” & $39.1^{\circ}$ & $21 \cdot 5^{0}$ & $01: 52: 51$ & 3.5 \\
\hline 17 & $"$ & 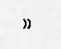 & $”$ & $39.0^{\circ}$ & $21.8^{\circ}$ & $02: 09: 49$ & 3.6 \\
\hline 18 & $"$ & $"$ & $”$ & $39.2^{\circ}$ & $21.5^{\circ}$ & $13: 24: 32$ & 4.0 \\
\hline 19 & $"$ & $"$ & $"$ & $39.3^{\circ}$ & $21.3^{\circ}$ & $15: 09: 13$ & 3.8 \\
\hline 20 & $n$ & $"$ & $"$ & - & - & $15: 10$ & 3.9 \\
\hline 21 & $"$ & 8 & $"$ & $39^{1} / 2^{0}$ & $21^{1 / 2} 2^{\circ}$ & $17: 22: 37$ & 3.5 \\
\hline 22 & $"$ & 9 & $"$ & - & 一 & $02: 23$ & 3.5 \\
\hline 23 & $"$ & $"$ & $n$ & $39.3^{\circ}$ & $21.6^{\circ}$ & $02: 37: 13$ & 3.6 \\
\hline 24 & $"$ & $"$ & $"$ & $39.1^{\circ}$ & $21.5^{\circ}$ & $06: 04: 39$ & 3.7 \\
\hline 25 & $”$ & $"$ & $"$ & $39.2^{\circ}$ & $21.6^{\circ}$ & $22: 09: 05$ & 3.6 \\
\hline 26 & $"$ & 10 & $”$ & $39.0^{\circ}$ & $21.9^{\circ}$ & $13: 21: 42$ & 4.1 \\
\hline 27 & $"$ & $"$ & $"$ & $39.3^{\circ}$ & $21.3^{\circ}$ & $16: 10: 41$ & 3.8 \\
\hline 28 & $"$ & $"$ & $"$ & $39.4^{\circ}$ & $21.9^{\circ}$ & $19: 45: 53$ & 3.6 \\
\hline 29 & $"$ & 11 & $"$ & $39.2^{\circ}$ & $21.1^{\circ}$ & $00: 57: 54$ & 3.7 \\
\hline 30 & $n$ & ” & $"$ & $39.3^{\circ}$ & $21.2^{0}$ & $05: 41: 21$ & 3.8 \\
\hline 31 & $"$ & $"$ & ") & $39.3^{\circ}$ & $21.3^{\circ}$ & $06: 49: 32$ & 3.8 \\
\hline 32 & $"$ & 12 & $n$ & $39^{1} / 4^{\circ}$ & $2 \mathrm{I}^{1 / 2} \mathrm{O}$ & $06: 07: 33$ & $3 .+$ \\
\hline 33 & $"$ & $n$ & " & $39 \cdot 5^{\circ}$ & $21.4^{\circ}$ & $13: 36: 13$ & 4.1 \\
\hline 34 & $"$ & 14 & $"$ & $39.2^{\circ}$ & $21 \cdot 3^{\circ}$ & $20: 16: 48$ & 4.1 \\
\hline 35 & $n$ & 15 & 1 & $39^{1 / 4^{0}}$ & $21^{1} / 4^{0}$ & $05: 20: 19$ & 3.5 \\
\hline 36 & $"$ & $"$ & $"$ & $39^{1} /^{0}$ & $21^{1 / 2}{ }^{0}$ & $22: 48: 20$ & 3.4 \\
\hline 37 & $"$ & 16 & $n$ & $38.9^{\circ}$ & $21.6^{\circ}$ & $07: 12: 27$ & 3.5 \\
\hline 38 & $"$ & $n$ & $"$ & $39.9^{\circ}$ & $21.8^{\circ}$ & $14: 59: 45$ & 3.4 \\
\hline
\end{tabular}


Continued

\begin{tabular}{|c|c|c|c|c|c|c|c|}
\hline No & & ate & & $p$ & $\lambda$. & Origin Time & $\underset{M_{L}}{\text { Magnitude }}$ \\
\hline 39 & Feb. & 17 & $n$ & $39.1^{\circ}$ & $21.6^{\circ}$ & $07: 37: 42$ & 3.7 \\
\hline 40 & $\eta$ & $"$ & $n$ & $39.1^{\circ}$ & $21.7^{\circ}$ & $10: 41: 20$ & 3.8 \\
\hline 41 & $"$ & $"$ & $"$ & $39.0^{\circ}$ & $21.6^{\circ}$ & $22: 04: 09$ & 3.6 \\
\hline 42 & $”$ & 19 & " & $39.1^{\circ}$ & $21.5^{\circ}$ & $10: 22: 25$ & 3.7 \\
\hline 43 & $"$ & 20 & $"$ & $39.2^{\circ}$ & $21.5^{\circ}$ & $08: 44: 24$ & 3.5 \\
\hline 44 & $"$ & $"$ & " & $39.4^{\circ}$ & $21.6^{\circ}$ & $09: 10: 53$ & 3.6 \\
\hline 45 & $"$ & 21 & $"$ & $39^{1 / 4^{\circ}}$ & $22.0^{\circ}$ & $09: 29: 59$ & 3.6 \\
\hline 46 & $"$ & 22 & $"$ & $39.2^{\circ}$ & $21.2^{\circ}$ & $10: 05: 32$ & 3.8 \\
\hline 47 & $"$ & 25 & ” & $39.2^{\circ}$ & $21 \cdot 2^{\circ}$ & $02: 46: 30$ & 3.5 \\
\hline 48 & $"$ & $"$ & $"$ & $39.2^{\circ}$ & $21.0^{\circ}$ & $12: 36: 21$ & 3.9 \\
\hline 49 & ” & 26 & ” & $39.1^{\circ}$ & $21.5^{\circ}$ & $02: 39: 18$ & 3.5 \\
\hline 50 & $"$ & 27 & $"$ & $39.2^{\circ}$ & $21.5^{0}$ & $14: 43: 37$ & 3.6 \\
\hline 51 & $"$ & $"$ & $"$ & $39.1^{\circ}$ & $21.6^{\circ}$ & $19: 39: 16$ & 3.8 \\
\hline 52 & $"$ & 28 & $"$ & $39.0^{\circ}$ & $21.9^{\circ}$ & $06: 46: 28$ & 3.6 \\
\hline 53 & March & 1 & 1966 & $39.2^{\circ}$ & $21 \cdot 4^{\circ}$ & $04: 48: 12$ & 3.6 \\
\hline 54 & $"$ & 6 & ” & - & - & $08: 51: 54$ & 3.4 \\
\hline 55 & $"$ & 8 & $"$ & $39.2^{\circ}$ & $21.2^{\circ}$ & $18: 51: 39$ & 4.4 \\
\hline 56 & $n$ & 9 & $"$ & - & -- & $07: 50: 52$ & 3.7 \\
\hline 57 & $n$ & 10 & $"$ & $39.2^{\circ}$ & $21 \cdot 1^{0}$ & $01: 23: 41$ & 3.8 \\
\hline 58 & $"$ & $n$ & $"$ & $39.2^{\circ}$ & $21 \cdot 1^{\circ}$ & $02: 33: 09$ & 4.0 \\
\hline 59 & $"$ & 11 & $"$ & $39.2^{\circ}$ & $21.3^{\circ}$ & $20: 19: 10$ & 4.0 \\
\hline 60 & $n$ & 12 & $"$ & $39.0^{\circ}$ & $21^{1 / 4^{0}}$ & $17: 04: 39$ & 3.5 \\
\hline 61 & $"$ & 13 & $"$ & $39.0^{\circ}$ & $21 \cdot 6^{\circ}$ & $19: 35: 49$ & 4.0 \\
\hline 62 & $n$ & 14 & $n$ & - & - & $14: 07$ & 3.8 \\
\hline 63 & $n$ & $n$ & $"$ & $39.2^{\circ}$ & $21 \cdot 4^{\circ}$ & $14: 08: 34$ & 4.0 \\
\hline 64 & $"$ & $n$ & $"$ & $39.5^{\circ}$ & $21.5^{0}$ & $14: 16: 05$ & 4.0 \\
\hline 65 & $n$ & 15 & $n$ & $39.3^{\circ}$ & $21.2^{\circ}$ & $10: 46: 07$ & 4.0 \\
\hline 66 & $"$ & $"$ & $"$ & $39.3^{\circ}$ & $21.3^{\circ}$ & $12: 18: 32$ & \pm .0 \\
\hline 67 & $"$ & $n$ & $"$ & - & - & $15: 51$ & 3.4 \\
\hline 68 & $n$ & $n$ & $n$ & $39.3^{\circ}$ & $21.3^{\circ}$ & $21: 02: 52$ & 3.7 \\
\hline
\end{tabular}


Continued

\begin{tabular}{|c|c|c|c|c|c|c|c|}
\hline No & & ate & & $p$ & $\lambda$ & Origrin Time & $\underset{M_{L}}{\operatorname{Magnitude}}$ \\
\hline 69 & March & 17 & $"$ & $38^{3} / 4^{0}$ & $21^{3 / 4^{0}}$ & $19: 25: 22$ & 3.4 \\
\hline 70 & $"$ & $"$ & $"$ & $\ldots$ & - & $20: 07$ & 3.4 \\
\hline 71 & $"$ & 21 & $"$ & $39.1^{\circ}$ & $21.7^{\circ}$ & $14: 32: 31$ & 3.6 \\
\hline 72 & $"$ & 26 & $"$ & $38.9^{\circ}$ & $21.9^{\circ}$ & $20: 17: 28$ & 3.8 \\
\hline 73 & $"$ & 28 & $"$ & $39.4^{\circ}$ & $21.4^{\circ}$ & $04: 04: 34$ & 4.0 \\
\hline 74 & $A_{p}$ ril & 1 & 1966 & $39.2^{\circ}$ & $21.2^{\circ}$ & $13: 14: 55$ & 4.4 \\
\hline 75 & $"$ & 2 & $"$ & $39.2^{\circ}$ & $21.4^{\circ}$ & $06: 38: 44$ & 3.4 \\
\hline 76 & $"$ & 3 & $"$ & $39.2^{\circ}$ & $21.3^{0}$ & $11: 36: 18$ & 4.6 \\
\hline 77 & $"$ & 5 & $n$ & $39.4^{\circ}$ & $21.6^{\circ}$ & $08: 07: 20$ & 4.2 \\
\hline 78 & $"$ & $n$ & $"$ & $39.2^{\circ}$ & $21.3^{\circ}$ & $13: 57: 24$ & 3.8 \\
\hline 79 & $"$ & 7 & $"$ & $39.2^{\circ}$ & $21.3^{\circ}$ & $12: 58: 42$ & 3.6 \\
\hline 80 & " & 12 & $n$ & $39.4^{\circ}$ & $20.3^{0}$ & $19: 14: 38$ & 3.6 \\
\hline 81 & $n$ & 18 & $"$ & $39.1^{\circ}$ & $21.5^{\prime \prime}$ & $08: 37: 05$ & 3.7 \\
\hline 82 & $"$ & $"$ & $n$ & $39.0^{\circ}$ & $21^{1 / / 2}{ }^{\circ}$ & $09: 59: 15$ & 4.3 \\
\hline 83 & $"$ & 19 & $"$ & $39.0^{\prime \prime}$ & $21.5^{0}$ & $02: 42: 54$ & 3.4 \\
\hline 84 & $"$ & 23 & $"$ & $39.2^{\circ}$ & $21.0^{\circ}$ & $11: 08: 03$ & 4.2 \\
\hline 85 & $n$ & 25 & $"$ & $39.2^{\circ}$ & $21.3^{0}$ & $01: 12: 21$ & 3.6 \\
\hline 86 & $n$ & $"$ & $"$ & $38.9^{\circ}$ & $21.3^{\circ}$ & $23: 18: 09$ & 3.7 \\
\hline 87 & $n$ & 26 & $"$ & $38^{3} / 4^{0}$ & $21^{1 / 20}$ & $05: 11: 59$ & 3.6 \\
\hline 88 & $"$ & 28 & $"$ & $39.6^{\circ}$ & $21.5^{\circ}$ & $01: 54: 19$ & 3.4 \\
\hline 89 & $"$ & $"$ & $n$ & $39.4^{\circ}$ & $20.9^{\circ}$ & $11: 47: 26$ & 4.4 \\
\hline 90 & May & 1 & 1966 & $39.0^{\circ}$ & $21.7^{\circ}$ & $15: 52: 25$ & 3.6 \\
\hline 91 & $n$ & 3 & $"$ & $39.2^{\circ}$ & $21.5^{\circ}$ & $12: 52: 35$ & 3.5 \\
\hline 92 & $"$ & 3 & $"$ & $39.3^{\circ}$ & $21.3^{\circ}$ & $12: 56: 14$ & 3.4 \\
\hline 93 & $"$ & 4 & $"$ & $39.3^{\circ}$ & $21.4^{\circ}$ & $01: 16: 33$ & 3.6 \\
\hline 94 & $"$ & $n$ & $"$ & $39.3^{\circ}$ & $21.3^{\circ}$ & $06: 36: 50$ & 5.1 \\
\hline 95 & $"$ & $n$ & $"$ & $39.2^{\circ}$ & $21.3^{\circ}$ & $07: 38: 50$ & 4.2 \\
\hline 96 & $"$ & 8 & $"$ & $39.3^{\circ}$ & $21.4^{\prime \prime}$ & $03: 48: 38$ & 3.8 \\
\hline 97 & $"$ & 11 & $"$ & $39.4^{\circ}$ & $21.0^{\circ}$ & $01: 07: 27$ & 3.9 \\
\hline 98 & $"$ & 12 & $"$ & $39^{1 / 4^{0}}$ & $21^{1 / 4^{\circ}}$ & $21: 58: 34$ & 3.6 \\
\hline
\end{tabular}


Continued

\begin{tabular}{|c|c|c|c|c|c|c|c|}
\hline$N^{\circ}$ & & ate & & $q$ & $\lambda$ & Origin Time & $\underset{M I_{L}}{\text { Maenitude }}$ \\
\hline 99 & May & 14 & 1966 & $391 /{ }^{\circ}$ & $21.0^{\circ}$ & $13: 36: 07$ & 3.4 \\
\hline 100 & $"$ & $"$ & $"$ & $39.0^{\circ}$ & $21^{3 / 2}{ }^{0}$ & $15: 11: 14$ & 3.4 \\
\hline 101 & $"$ & $"$ & $"$ & $-\cdots$ & $\cdots-$ & $15: 31$ & 3.4 \\
\hline 102 & $n$ & 15 & $"$ & $39.2^{\circ}$ & $21.0^{\circ}$ & $08: 29: 30$ & 3.9 \\
\hline 103 & $"$ & $"$ & " & - & -.- & $09: 30$ & 3.4 \\
\hline 104 & $"$ & 22 & $"$ & $39.2^{\circ}$ & $21.0^{\circ}$ & $07: 42: 17$ & 3.8 \\
\hline 105 & " & $"$ & $"$ & $39.3^{\circ}$ & $20.8^{\circ}$ & $11: 15: 36$ & 4.0 \\
\hline 106 & $"$ & 23 & $"$ & $39.1^{\circ}$ & $21.7^{\circ}$ & $01: 15: 57$ & 3.4 \\
\hline 107 & $"$ & 26 & $"$ & $39.0^{\circ}$ & $21.3^{\circ}$ & $06: 32: 16$ & 3.8 \\
\hline 108 & $"$ & 27 & $"$ & $38.9^{\circ}$ & $21.7^{\circ}$ & $23: 14: 24$ & 3.6 \\
\hline 109 & $n$ & 28 & $n$ & $38^{3} / 4^{\circ}$ & $2 I^{1} / 2^{o}$ & $10: 15: 27$ & 3.4 \\
\hline 110 & $n$ & 29 & $"$ & $39.3^{\circ}$ & $21.1^{\circ}$ & $18: 38: 29$ & 3.4 \\
\hline 111 & June & 1 & 1966 & $39^{1} / 2^{\circ}$ & $21^{1 / 2^{\circ}}$ & $21: 15: 57$ & 3.4 \\
\hline 112 & $n$ & 4 & $"$ & $39.0^{\circ}$ & $21.5^{\circ}$ & $07: 06: 19$ & 3.8 \\
\hline 113 & $"$ & 11 & $"$ & $38.8^{\circ}$ & $21.5^{\circ}$ & $10: 21: 52$ & 4.2 \\
\hline 114 & $"$ & 13 & $n$ & $39^{1} / 2^{\circ}$ & $21.0^{\circ}$ & $11: 44: 52$ & 4.0 \\
\hline 115 & $n$ & 15 & $"$ & $39.0^{\circ}$ & $21.5^{\circ}$ & $01: 46: 27$ & 3.5 \\
\hline 116 & $"$ & $"$ & $"$ & $38^{3} / 4^{\circ}$ & $21^{1 / 2}{ }^{0}$ & $05: 21: 54$ & 3.4 \\
\hline 117 & $"$ & 23 & $"$ & $39.2^{\circ}$ & $22.1^{0}$ & $21: 02: 53$ & 3.6 \\
\hline 118 & $"$ & 24 & $"$ & $39.2^{\circ}$ & $21.3^{\circ}$ & $01: 24: 29$ & 3.8 \\
\hline 119 & $"$ & $"$ & $"$ & $38.7^{\circ}$ & $21.6^{\circ}$ & $22: 34: 24$ & 4.4 \\
\hline 120 & July & 15 & 1966 & $38.9^{\circ}$ & $21.4^{0}$ & $23: 50: 0 \tau$ & 4.2 \\
\hline 121 & $n$ & 20 & $n$ & $39.0^{\circ}$ & $21.5^{\circ}$ & $10: 16: 02$ & 4.1 \\
\hline 122 & $"$ & 21 & $n$ & $39.2^{\circ}$ & $21.1^{\circ}$ & $03: 56: 44$ & 3.6 \\
\hline 123 & $n$ & $"$ & $n$ & $39.4^{\circ}$ & $21.0^{0}$ & I $1: 30: 50$ & 3.4 \\
\hline 124 & $n$ & 22 & $n$ & $\cdots$ & 一 & $09: 46$ & 3.5 \\
\hline 125 & $"$ & 23 & $"$ & $89.0^{\circ}$ & $21.8^{\circ}$ & $05: 28: 28$ & 3.7 \\
\hline 126 & $n$ & 24 & $n$ & $38.8^{\circ}$ & $21.9^{\circ}$ & $01: 27: 39$ & 3.6 \\
\hline 127 & $n$ & 24 & $n$ & $38.9^{\circ}$ & $22.0^{\circ}$ & $01: 32: 48$ & 4.4 \\
\hline 128 & $n$ & $"$ & $"$ & $39.0^{\circ}$ & $22.0^{\circ}$ & $02: 11: 08$ & 3.6 \\
\hline 129 & $"$ & 28 & $"$ & $39.2^{\circ}$ & $21.3^{\circ}$ & $13: 09: 58$ & 3.8 \\
\hline 130 & $"$ & 30 & $"$ & $39^{3} / 4^{\circ}$ & $21^{3} 4^{\circ}$ & $08: 35: 37$ & 3.8 \\
\hline
\end{tabular}


Continued

\begin{tabular}{|c|c|c|c|c|c|c|c|}
\hline No & & ate & & $p$ & $\lambda$. & Origin Time & $\underset{M_{L}}{\operatorname{Magnit}}$ \\
\hline 131 & Aug. & & 1966 & $39.0^{\circ}$ & $21.0^{\circ}$ & $23: 58: 48$ & 3.5 \\
\hline 132 & ” & 8 & $n$ & $39.5^{\circ}$ & $21.3^{\circ}$ & $11: 07: 32$ & 3.5 \\
\hline 133 & $”$ & $"$ & $n$ & $39.6^{\circ}$ & $21.0^{\circ}$ & $12: 34: 07$ & 4.0 \\
\hline 134 & ” & 9 & $n$ & $39.5^{\circ}$ & $21.4^{0}$ & $20: 20: 48$ & 4.0 \\
\hline 135 & $"$ & 11 & $"$ & $38.8^{\circ}$ & $21.7^{\circ}$ & $04: 34: 12$ & 4.2 \\
\hline 136 & $"$ & 12 & " & $39.2^{\circ}$ & $21.2^{\circ}$ & $05: 21: 59$ & 3.6 \\
\hline 137 & ” & 16 & $"$ & $39.4^{\circ}$ & $20.5^{\circ}$ & $03: 28: 45$ & 3.5 \\
\hline 138 & ” & $"$ & $"$ & $39.5^{\circ}$ & $20.6^{\circ}$ & $13: 46: 26$ & 3.4 \\
\hline 139 & $"$ & 17 & $n$ & $39.6^{\circ}$ & $20.5^{\circ}$ & $08: 21: 56$ & 3.5 \\
\hline 140 & $"$ & $n$ & $"$ & $38.8^{\circ}$ & $21.8^{\circ}$ & $16: 16: 26$ & 3.7 \\
\hline 141 & $"$ & $"$ & " & $39.4^{\circ}$ & $21.3^{0}$ & $19: 02: 01$ & 3.8 \\
\hline 142 & $n$ & 20 & $"$ & $38.6^{\circ}$ & $21.5^{\circ}$ & $11: 54: 07$ & 3.8 \\
\hline 143 & $"$ & $"$ & $n$ & $39.2^{\circ}$ & $21.4^{\circ}$ & $19: 49: 38$ & 3.6 \\
\hline 144 & $"$ & 31 & $n$ & $39.0^{\circ}$ & $21.5^{\circ}$ & $01: 20: 36$ & 3.4 \\
\hline 145 & $"$ & $n$ & $"$ & $39^{1 / 4^{\circ}}$ & $20^{3} \div$ & $10: 15: 04$ & 3.4 \\
\hline 146 & sept. & 9 & 1966 & $39.1^{\circ}$ & $20.9^{\circ}$ & $11: 34: 39$ & 3.5 \\
\hline 147 & $"$ & 14 & $n$ & $39.0^{\circ}$ & $21.3^{\circ}$ & $14: 42: 44$ & 3.5 \\
\hline 148 & $"$ & 23 & $"$ & $39.5^{\circ}$ & $20.5^{\circ}$ & $23: 47: 48$ & 4.2 \\
\hline $1+9$ & oct. & 3 & 1966 & $38.9^{\circ}$ & $20.8^{\circ}$ & $13: 15: 29$ & 3.7 \\
\hline 150 & " & 17 & $"$ & $39.4^{\circ}$ & $20.9^{\circ}$ & $12: 59: 45$ & 3.6 \\
\hline 151 & " & 28 & $"$ & $39.2^{\circ}$ & $21.2^{\circ}$ & $09: 52: 47$ & 3.5 \\
\hline 152 & $"$ & 29 & $"$ & $38.8^{\circ}$ & $21.0^{\circ}$ & $02: 39: 25$ & 5.6 \\
\hline 153 & $"$ & $"$ & $"$ & $38.9^{\circ}$ & $21.0^{\circ}$ & $03: 05: 20$ & 3.3 \\
\hline 154 & $"$ & $"$ & ” & $39.0^{\circ}$ & $20.9^{\circ}$ & $17: 50: 56$ & 3.6 \\
\hline 155 & $"$ & 30 & $"$ & $38.8^{\circ}$ & $21.5^{\circ}$ & 02:10:09 & 3.7 \\
\hline 156 & Nov. & 2 & 1966 & $38.9^{\circ}$ & $21.1^{\circ}$ & $19: 01: 21$ & 3.2 \\
\hline 157 & $"$ & 15 & $"$ & $38.7^{\circ}$ & $20.8^{\circ}$ & $22: 12: 05$ & 3.7 \\
\hline 158 & $"$ & 16 & $"$ & $38.8^{\circ}$ & $21.1^{\circ}$ & $02: 57: 58$ & 3.7 \\
\hline 159 & $"$ & 20 & $"$ & $38.9^{\circ}$ & $21.1^{\circ}$ & $14: 43: 09$ & 3.6 \\
\hline 160 & $"$ & 27 & $n$ & $39.5^{\circ}$ & $20.8^{\circ}$ & $06: 05: 05$ & 3.8 \\
\hline 161 & $"$ & $n$ & $"$ & $39.5^{\circ}$ & $20.5^{\circ}$ & $10: 46: 17$ & 3.9 \\
\hline
\end{tabular}


magnitudes of all shocks of the sequence with $M_{L} \geqslant 3.4$, are listed in Table $I$. According to Romney ( $\left.{ }^{-}\right)$the local magnitude $M_{L}$ is related with the surface wave magnitude by $M_{s}=M_{L}+0.44$. From the magnitude of each shock the deformation has been calculated by using the formula:

$$
\log D=5.17+1.46 M
$$

given by Bath and Duda $\left({ }^{13}\right)$.

Fault plane solution of the main shock has been determined graphically by $\mathrm{N}$. Delibasis by using $P$ wave data of 80 stations. Solution also has been found by using Wickens' program in an IBNI 1620 computer. The two solutions are similar and we have finally adopted the following one determined by the computer. Nodal Plane $a\left(\mathrm{~N} 114^{\circ} \mathrm{E}, 76^{\circ} \mathrm{dip}\right.$ ), Nodal Plane $b$ (N $8^{\circ} \mathrm{W}, 24^{\circ} \mathrm{dip}$ ), Plane of action $\left(\mathrm{N} \mathrm{30} 0^{\circ}, 51^{\circ} \mathrm{dip}\right)$. Later we shall present evidence that plane $(a)$ is the fault plane. The kind of faulting is reverse and sinistral.

All these observations have been used to find spatial, time, and magnitude distribution and deformation characteristics of the foreshocks and aftershocks of the sequence. Then, these data were compared with theoretical and experimental results to present evidence of existing relation between the water reservoir and seismic activity.

\section{SPATIAL DISTRIBUTION OF FORESHOCKS AND AFTERSHOCKS.}

The epicenters of all earthquakes of the sequence with $M_{L} \geqslant 3.4$ are shown on the index map of Figure 1. The foreshocks are denoted by triangles, the aftershocks by circles and the late aftershocks by squares. By "late aftershocks" we mean the earthquake of magnitude $M_{L}=5.6$ which occurred on October 29, 1966 (about nine months after the main shock), as well as its own aftershocks. The epicenter of this large late aftershock is close to Katuna about $55 \mathrm{~km}$ southwest of the epicenter of the principal earthquake. From the distribution of the epicenters of the foreshocks and normal aftershocks we can safely conclude, that the determined by first motions of $P$ waves plane (a), which strikes $\mathrm{N} 114^{\circ} \mathrm{E}$ is the main fault responsible for this sequence. This is an almost vertical thrust fault and the lake is on the sinking block. The strike of this fault is also indicated in Figure 1. The distribution of the epicenters indicates that other minor faults gave some shocks. One of these minor faults is the fault of the late aftershocks. This fault strikes in an almost east-west 
direction. As we can see in Figure 1 the aftershock region of the late aftershocks do not coincirle with the rigion of the foreshocks and normal aftershocks. No accurate epicenter determination was

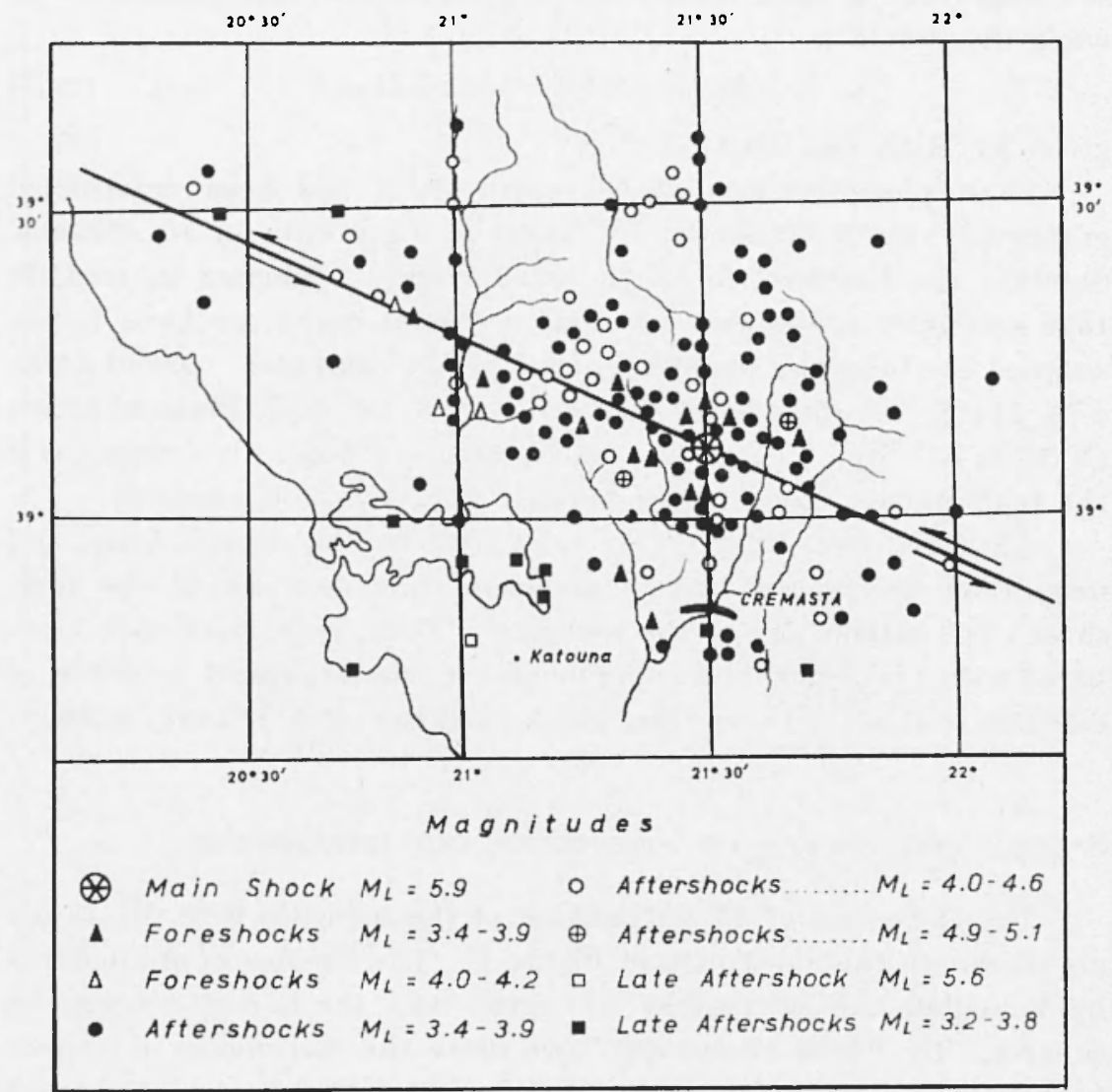

Fig. 1 - Index map of the location of epicenters of foreshocks and aftershocks.

possible for the small shocks of the sequence. Macroseismic evidence indicates that most of the small foreshocks were very shallow and their epicenter were just below or very close to the Cremasta lake. This is supported by the fact that most of the epicentral distances from Valsamata are almost equal to the distance between the lake and the station.

As we have already noted the existence of very strong crustal phases $P g, S g$ in comparison with $P n$ and $S n$ phases indicates, that 
the foci of the shocks were not close to the Mohorovicic discontinuity or in the mantle. The time difference between $P n$ and $P g$ of the main shock measured on the same record at the station in Athens is 4.1 seconds, and the distance between Athens and epicenter is $220 \mathrm{~km}$. Work on crustal structure, carried out now in the region, indicated that the mean crustal velocity of longitudinal waves is $6.2 \mathrm{~km} / \mathrm{sec}$ and the $P n$ velocity is $7.9 \mathrm{~km} / \mathrm{sec}$. If we use these velocities and take the mean crustal thickness between epicenter and station equal to $40 \mathrm{~km}$, we can apply the following formula for an approximate determination of the focal depth of the main shock:

$$
\delta t=\Delta\left(\frac{v-v_{1}}{v v_{1}}\right)+\frac{(2 d-h) \sqrt{v^{2}-v_{1}^{2}}}{v v_{1}}
$$

where $d$ is the crustal thickness, $A$ the epicentral distance, $\delta t$ the time difference between $P n$ and $P g, v$ and $v_{1}$ the longitudinal crustal and $P n$ velocity, respectively, and $h$ the focal depth. Application of the formula gives a focal depth equal to $23 \mathrm{~km}$.

A tentative empirical formula has been derived by Papazachos et al. (11), which relates the magnitude of the main shock with the magnitude of the largest normal aftershock and the focal depth of the main shock. This formula gives a focal depth equal to $24 \mathrm{~km}$. Other tentantive empirical relations have been derived, which connect the magnitude of the main shock and the number of aftershocks or the parameter $b^{\prime}$ of the magnitude dictribution with the focal depth. These relations give a focal depth even smaller. Macroseismic determination of the focal depth of the main shock also indicatel that the shock was shallow. We feel that we are right, if we say, that the focal depth is of the order of $20 \mathrm{~km}$.

\section{TIME DIS'TRIBUTION OF FORESIIOCKS AND AFTERSHOCKS.}

Mogi $\left({ }^{15}\right)$ showed that the time distribution of aftershocks in the early stage after the main shock is expressed by the relation:

$$
n(t) d t=n_{1} t^{-h} d t \quad 0<t<t_{o}
$$

where $t$ is the time measured from the origin time of the main shock, $n(t) d t$ is the number of aftershocks which occur between $t$ and $t+d t$ 
and $n_{1}$ is a constant. Papazaclios et al $\left({ }^{14}\right)$ determined the cumulative frequency of many earthquakes in the region of Greece:

$$
N(t)=\int_{t}^{t_{0}} n(t) d t
$$

and they found that functions of the following type fit the data:

$$
N=N, t^{-H} \quad t<t_{0} .
$$

The mean value of the constants $H$ for the region of Greece was found equil to 0.40 . The constant $h$ and $H$ depend probably on the viscosity of the material in the aftershock region.

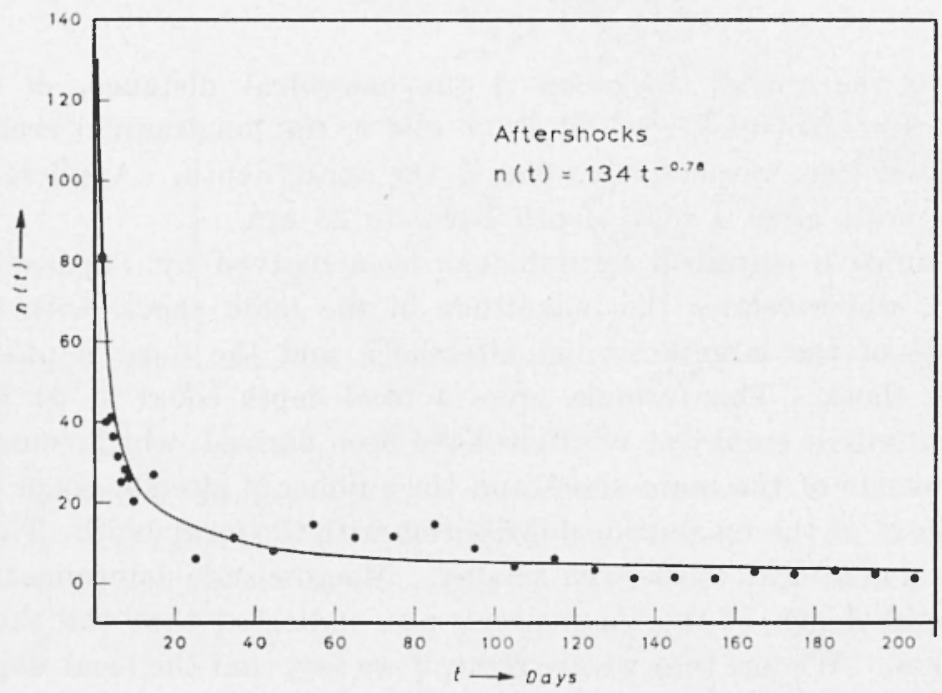

Fig. 2 - Time distribution of aftershocks.

The time distribution of the aftershocks of the Cremasta lake earthquake is shown in Figure 2.

The following relation fit well the data:

$$
n(t)=134 t^{-0.78} \text {. }
$$

The time is measured from the main shock. The time interval was taken equal to one day.

The time distribution of the foreshocks is shown in Figure 3. A relation of the form [t] with positive exponent fits the data. If 
we measure the time from December 4 and consider the time interval dt equal to one day, the following relation gives the number of foreshocks which occurred in the $t^{\text {th }}$ day:

$$
\log n(t)=-0.30+0.03 t \text {. }
$$

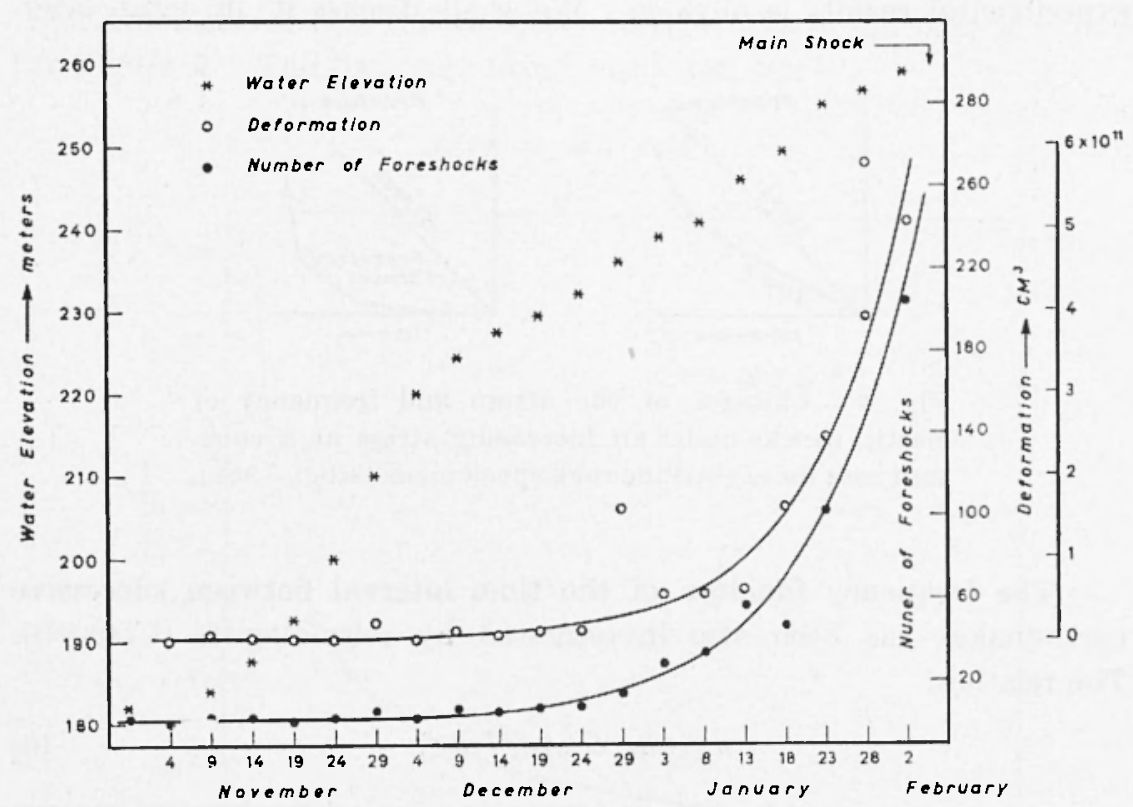

Fig. 3 - Time distribution and deformation caracteristic of foreshocks, and variation with time of the water elevation of the artificial lake.

The variation of the deformation in the foreshock region with time, calculated by the formula [2], is also plotted in Figure 3. The water level variation in the lake is presented in the same Figure. We see that the variation with time of the pressure exerted by the water on the rocks of the bottom of the lake was almost linear between December 4 and February 5, when the main shock occurred and the frequency of shocks and deformation increased almost exponentially. The material in the foreshock region is heterogenous and brittle, because strong evidence exists, that the source of the foreshocks was shallow. If the lake has influenced the generation of foreshocks we can then conclude from Figure 3 that, when the stress exerted on heterogenous brittle material increases at constant rate, the frequency of shocks and the deformation must increase almost exponentially. In fact 
laboratory experiments carried out by Mogi $\left({ }^{16}\right)$ has shown that this is true. The change of strain and frequency of elastic shocks under an increasing stress at a constant rate for heterogenous brittle material, as it is reported by Mogi, is shown in Figure 4. The qualitative resemblance between our observational data and Mogi's experimental results is obvious. We shall discuss it in detail later.
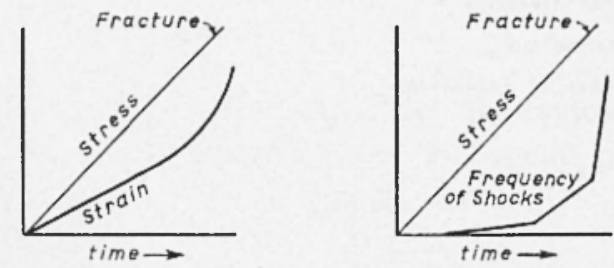

Fig. 4 - Changes of the strain and frequency of elastic shocks under an increasing stress at a cons. tant rate for crystalline rock speciemens (Mogi, 1962).

The frequency function of the time interval between successive earthquakes has been also investigated by seismologists (Utsu $\left({ }^{17}\right)$ ). The relation:

$$
n(\tau) d \tau=A e^{-\lambda . \tau} d \tau,
$$

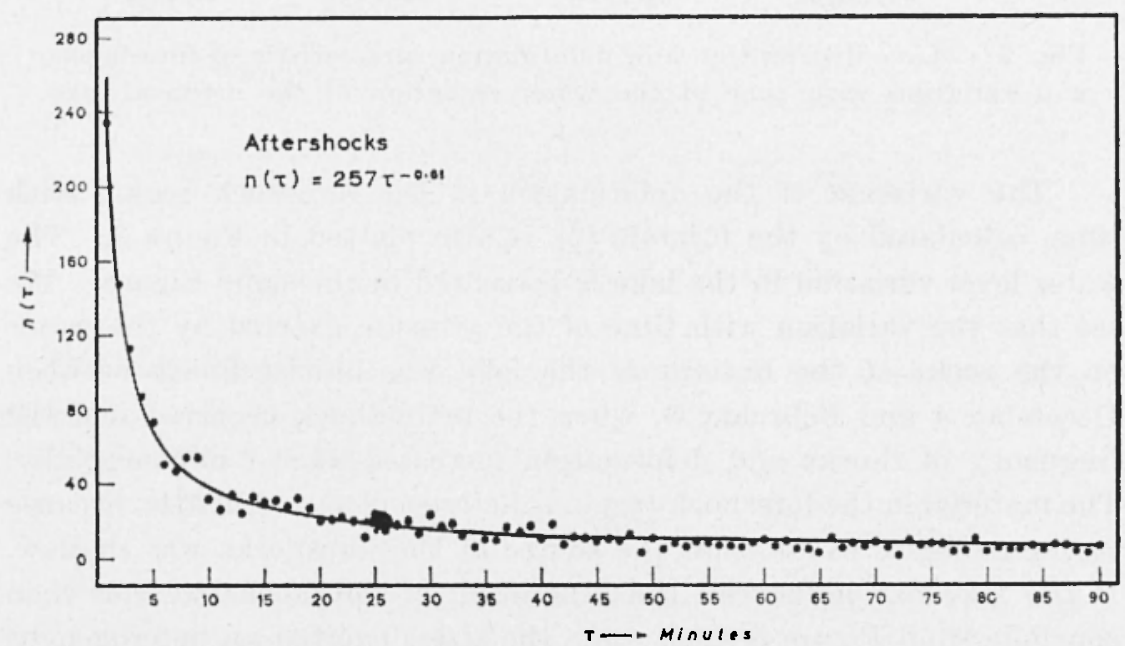

Fig. :5 - Frequency function of the time interval between successive aftershocks. 
is applied in ordinary earthquakes, and the relation:

$$
n(\tau) d \tau=a \tau^{-\hat{\rho}} d \tau
$$

in aftershock sequences; $\tau$ is the time interval between successive earthquakes and $A, \lambda, a, \beta$ are constants. The frequency function of the time interval between successive aftershocks in our case is plotted in Figure 5. The data are fitted very well by:

$$
n(\tau)=25 \tau^{-0.81}
$$

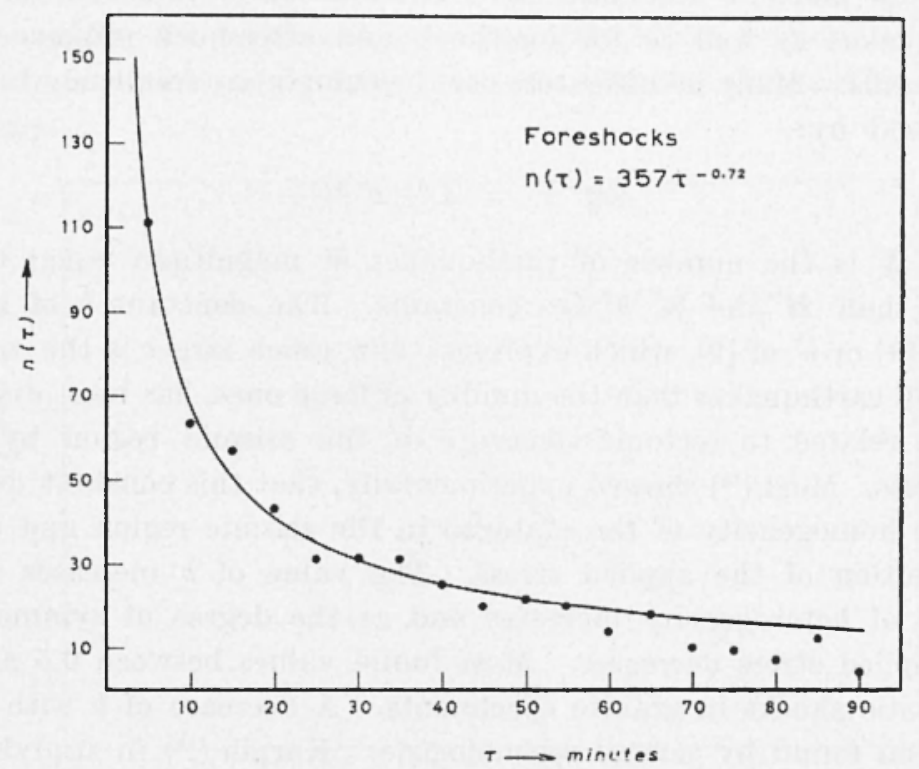

Fig. 6 - Frequency function of the time interval between suecessive foreshocks.

In deriving this equation the time interval was taken equal to one minute.

The frequency function of the time interval between successive foreshocks is plotted in Figure 6. Both [6] and [7] were tried. It was found that for foreshocks a relation of the type [i] also applies.

This relation fits very well the data and is:

$$
n(\tau)=357 \tau^{-0.72} .
$$

The time interval has been taken equal to 5 minutes. 
Frequency function of magnitude.

It is well known that the frequency function of the magnitude of earthquakes is expressed by:

$$
\log n=a+b(8-M) \text {, }
$$

given by Gutenberg and Richter $\left({ }^{18}\right)$. $n$ is the number of earthquakes confined to a certain domain and having magnitude between $H$ and $M+d M$ and $a, b$ are constants. The relation [8] holds for ordinary earthquakes as well as for foreshock and aftershock sequences and for swarms. Many investigators use the cumulative frequency function expressed by:

$$
\log N=A+b^{\prime} M
$$

where $N$ is the number of earthquakes of magnitude equal to and larger than $M$ and $A, b^{\prime}$ are constants. The constant $b$ of the relation [8] or $b^{\prime}$ of [9], which expresses how much larger is the number of smiall earthquakes than the number of large ones, has been discussed and is related to tectonic structure of the seismic region by some scientists. Mogi $\left({ }^{15}\right)$ showed experimentally, that this constant depends on the homogeneity of the material in the seismic region and on the distribution of the applied stress. The value of $b$ increases as the degree of heterogeneity increases and as the degree of symmetry of the applied stress decreases. Mogi found values between 0.5 and 1.0 for elastic shocks in granite speciments. A decrease of $b$ with depth has been found by several seismologists. Karnik ( $\left.{ }^{19}\right)$ in studying the seismicity in Europe found evidence for a decrease of $b$ with depth. Galanopoulos $\left({ }^{* 0}\right)$ determined constant $b^{\prime}$ and found a value equal to 0.82 for shallow ordinary earthquakes in the region of Greece and a value equal to 0.42 for earthquakes with intermediate focal depth of the same region. Papazachos et al (1.1) studied aftershock sequences in the region of Greece and gave the following tentative relation between $b^{\prime}$ and depth $h$ :

$$
b^{\prime}=1.26-0.013 h \quad 14 \mathrm{~km}<h<70 \mathrm{~km},
$$

$h$ is measured in $\mathrm{km}$. There is some evidence that constant $b^{\prime}$ at focal depths smaller than $14 \mathrm{~km}$ has even larger values than those predicted by [10]. The party of the seismographic observation of Matsushiro Earthquakes $\left({ }^{22}\right)$ studied an earthquake swarm in Mat- 
sushiro. They found a value equal to 1.34 for $b$. The mean focal depth of these shocks is about $4 \mathrm{~km}$. Drakopoulos divided the region of Greece in several parts and determined $b^{\prime}$ for each part by using many aftershock sequences for each case. He found for almost all parts, values between about 0.4 and 1.5. This is an indication that $b^{\prime}$ varies much more vertically than horizontally.

It has been found by many seismologists [Mogi $\left(^{15,16}\right)$, Suyehiro (:-), Papazachos et al $\left.\left({ }^{11}\right)\right]$ that the values of $b$ or $b^{\prime}$ are larger for aftershocks than for foreshocks. Mogi $\left({ }^{18}\right)$ showed experimentally that, when foreshocks and aftershocks come from the same volume, the value of $b$ is smaller for foreshocks than for aftershocks, because the main shock causes new cracks and thus the number of irregular points increases.

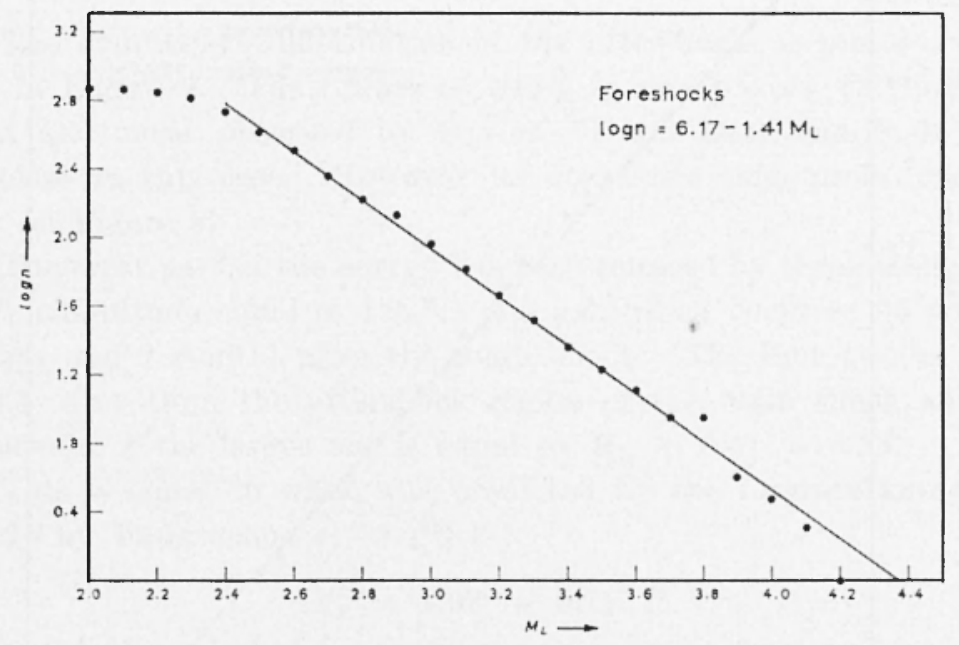

Fig. 7 - Cumulative frequency function of the magnitude of foreshocks.

The logarithm of the cumulative frequency function $N(M)$ of the magnitude of the foreshocks of the Cremasta lake earthquake is plotted versus $M$ in Figure 7. The following relation fits the data in the least square sense:

$$
\log N=6.17-1.41 M_{L}
$$

This relation fits well te data for magnitudes larger than 2.4. For $M<2.4$ the number of shocks is much smaller than that expected by [11]. This is partly due to the fact that some of the shocks of 
this range of magnitude have been omitted, because their recorded amplitudes were too small to measure. It is, however, very probable that this drop of the number of shocks, for very small magnitudes, is partially real. The value of $b^{\prime}$ is too large in comparison with values determined for other foreshock sequences of the region of Greece or othel regions. This is an other evidence, that the foreshock region of the Cremasta lake sequence is very shallow. The following relation expresses the cumulative frequency function of the magnitude $M_{L}$ of the aftershocks of the Cremasta lake earthquake:

$\log N=5.99-1.12 M_{L}$.

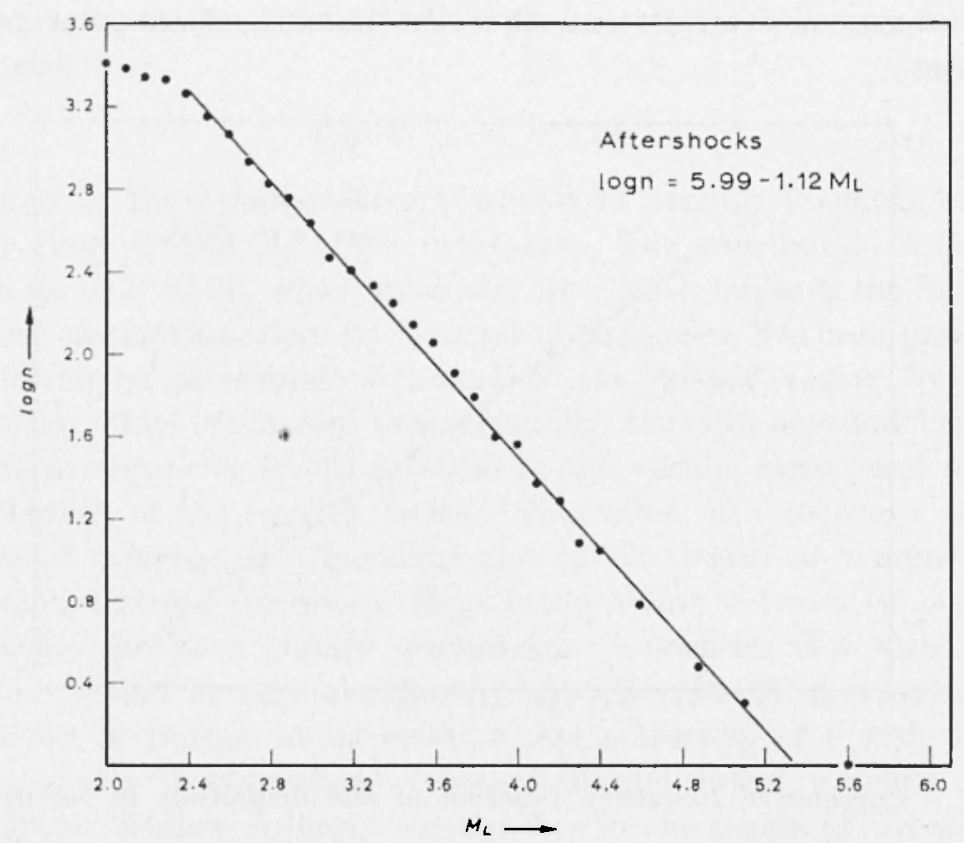

Figr. 8 - Cumulative frequency function of the magnitude of aftershocks.

The data are plotted in Figure 8. One can again observe, that the points for shocks of $M_{L}<2.4$ are below the line, which fits the data for $M_{L}>2.4$. The same phenomenon is observed in the frequency function of magnitude, which is given by the Japanese Party of the Seismographic: Observation of Matsushiro Larthquakes ( $\left.{ }^{21}\right)$. The fact that the change of the slope of their curve occurs at about the same magnitude, although they used different instruments with different magnification, probably suggests, that this change is real. 
The constant $b^{\prime}$ of the aftershocks has a value equal to 1.12, which is smaller by an anount equal to 0.29 than the corresponding value for foreshocks. This is in striking disagreement with what is known up to now on this matter. The fact that the epicentral regions of the foreshocks and aftershocks are not different, suggests that the larger value of $b^{\prime}$ for foreshocks must probably be attributed to the smaller mean depth of the foreshock volume than the mean depth of aftershock volume. The value of $b^{\prime}$ which has been calculated from data of ordinary shocks of this region (Galanopoulos, personal communication) is 0.64 .

\section{DEFORMA'LION CHARACTEIISTIOS.}

The cumulative deformation of the aftershocks is plotted versus time in Figure 9. The release of strain in two phases, the compressional and shear observed by Beniofl $\left({ }^{23}\right)$ and Bath and Duda $\left({ }^{13}\right)$ is not clear in this case. However we can make some useful observations on Figure 9.

The most part of the energy has been released by three aftershocks of $M_{L}$ magnitude equal to $4.9,5.1$ and 5.6, which occurred 56 minutes 98 days and 9 months after the main shock. The first two of these shocks came from the aftershock region of the main shock and the magnitude of the larger one is equal to $M_{L}+0.44=5.54$.

This is equal to what was predicted by the formula found previously by Papazachos at al. $\left({ }^{14}\right)$ :

$$
M_{1}=1.07+0.71 M
$$

where $M-6.3$ is the magnitude of the main shock.

The group for the study of aftershock sequences in the region of Greece has observed a third phase in the deformation curve in more than 30 per cent of the 60 cases studied. The earthquakes of this phase were named "late aftershocks". It was found that "the large late aftershocks have their own aftershocks. This indicates that the largest part of the aftershock region is not included in the aftershock volume of the main shock. This is supported by the fact that in most cases there is strong evidence that the epicenter of the large late aftershosk is out of the primary aftershock region. It is probable that the release of the main shock affects the state of the strained region of the large late aftershock and reduces the strength of the region by breaking through the 
barriers of some of its locks". A late phase is observed in the present case, too. The large late aftershock of the Cremasta Lake earthquake is the earthquake of magnitude $M_{L}=5.6$. The epicenter of this

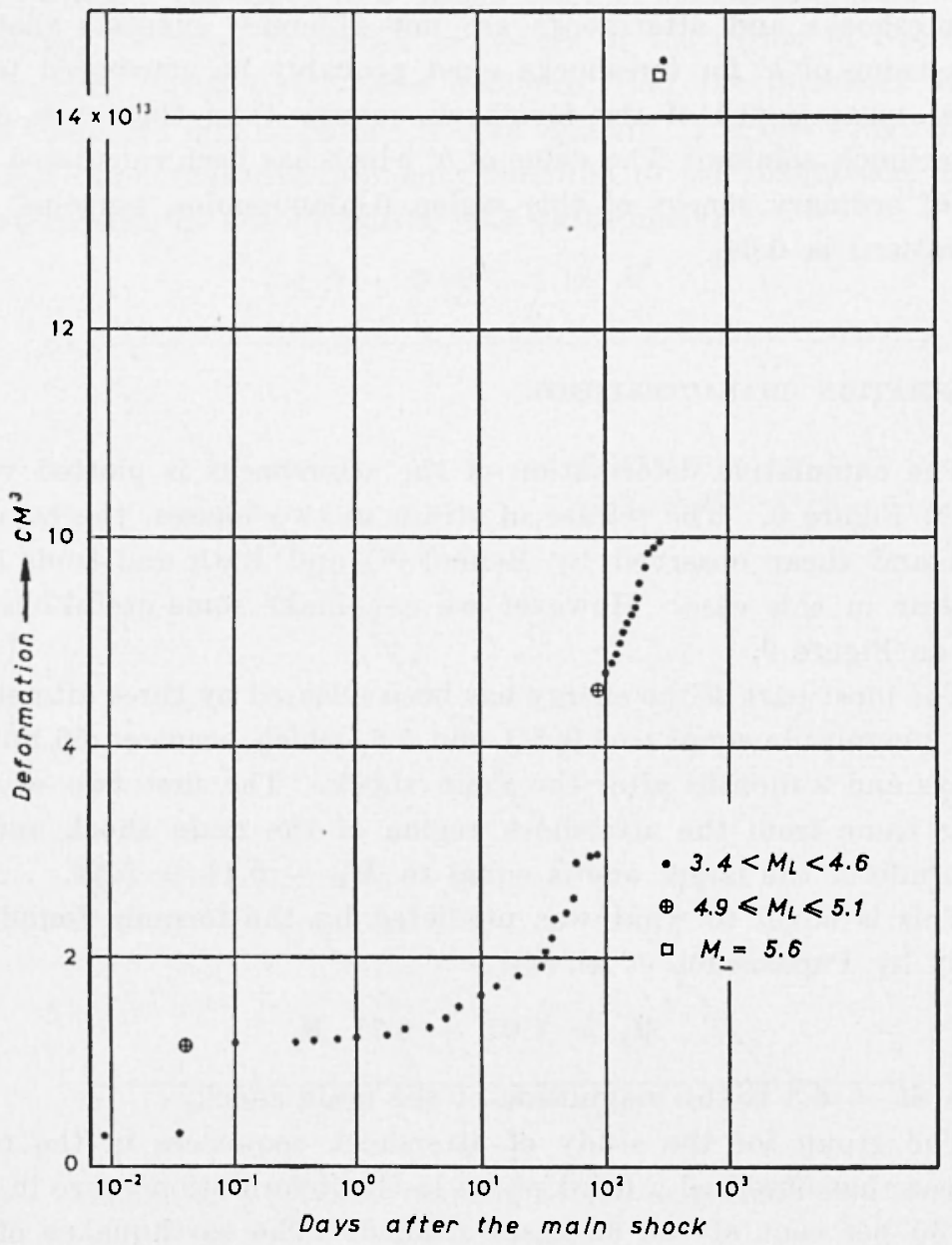

Fig. 9 - Deformation characteristics of aftershocks.

shock is close to Katouna, about $55 \mathrm{~km}$ southwest of the epicenter of the main shock. The late aftershock has its own aftershocks. These secondary aftershocks are distributed along a fault which strikes from east to west and intersects the main fault close to the Cremasta dam. Clearly, the largest part of the aftershock region of the late aftershocks is not included in the main aftershock volume (Fig. 1). 
As we have already seen, the deformation for the foreshocks (not the cumulative deformation) is plotted against time in Figure 3. The following relation fits the data well:

$$
\log D=-2.98 \div 0.07 t \text {. }
$$

The time interval has been taken equal to five days.

\section{FURTHER EVIDENCE FOR EXISTING RELATION BETWEEN WATER LOADING} in the CRemasta Lake aND Earthquake aCtivity.

The Cremasta dam is an earth fill dam which retains a reservoir containing water of maximum weight of the order of $10^{\circ}$ tons. The bottom and top of the artificial lake is $144 \mathrm{~m}$ and $287 \mathrm{~m}$ above sea level, respectively. The lake lias been made by damming the rivers Acheloos, Tavropos and Agrafiotis at their confluence point near Cremasta. The inpounding of the lake started on July 21, 1965 and on November 9, 1965 the surfare of the water was $185 \mathrm{~m}$ above sea level. After the middle of November a considerable change in the rate of water loading occurred. This is shown in Figure 3 . The force exerted by the water on the rocks is small compared to the forces acting at the focal region of earthquakes. However, the tectonic equilibrium was so delicate as to make it possible for the water loading to act as a triggering force. On the other hand, it is possible that the water under pressure was flowing in the fractures of the crust and reduced the frictional resistance. Thus the shear strength was reduced and movement of rock masses was facilitated. This, however, is only a possibility and no check is possible by observation. Direct comparison of the available observations with results of exerimental and theoretical investigation of the fracture of material is necessary. Since foreshocks occurred in the uppermost part of the crust, comparison of observations must be made with results of experiments carried out on heterogeneous brittle material.

Mogi $\left({ }^{16}\right)$ defines the transition probability of fracture $\mu(t) d t$ as:

$$
\mu(t) d t=-\frac{d N(t)}{N(t)},
$$

where $N(t)$ is the cumulative time distribution function. Mogi showed experimentally that:

$$
\mu(t)=A e^{\beta \sigma(t)}
$$


where $\sigma(t)$ is the stress and $A, b$ constant. For granite he found $A=4.0 \times 10^{-18} \mathrm{~min}^{-1}$ and $\beta=0.37 \mathrm{~cm}^{2} / \mathrm{kg}$.

From [12] and [13] we find:

$$
\left.N(t)=N_{0} \exp \left[-\int_{0}^{t} \mu(t) d t\right]\right]
$$

and

$$
\left.n(t)=\frac{d N(t)}{d t}=N_{\circ} \mu(t) \exp \mid-\int_{0}^{t} \mu(t) d t\right\rfloor
$$

or

$$
n(t)=N_{0} A e^{\hat{\rho} \sigma(\zeta)} \cdot \exp \left[-A \int_{0}^{t}{ }_{2} \beta \sigma(t) d t\right] .
$$

$N_{\circ}$ is the total number of recorded shocks. In our case we can put:

$$
\sigma(t)=\sigma_{o}+r t
$$

where $\sigma_{o}$ is the stress due to tectonic forces plus the stress exerted by the water on the rocks of the foreshock region on December 4 , 1965. We choose the zero time point at the beggining of December for two reasons. The first is that after that time the shocks became very frequent and a representative sample of earthquakes has been recorded. After that time the frequency of felt earthquakes increased and people worried much. The second reason is that after that time till the origin of the main shock the water level varied with time almost linearly and [17] is valid. Thus we avoid the application of numerical methods.

From [16] and [17] we receive:

$$
n(t)=N \cdot A e^{\beta\left(\sigma_{o}+r t\right)} \cdot \exp \left[A \stackrel{A^{\beta \sigma_{o}}}{\beta r}\left(1-e^{\beta r t}\right)\right]
$$

or

$$
\ln n(t)=\ln \left(A N_{o}\right)+\beta\left(\sigma_{0}+r t\right)+A \frac{e^{\beta \sigma_{o}}}{\beta r}\left(1-e^{\beta r t}\right)
$$

The value of $r$ is $0.067 \mathrm{~kg} / \mathrm{cm}^{2} /$ lay. Assuming with Berg $\left(^{5}\right)$ an upper limit equal to about $30 \mathrm{~kg} / \mathrm{cm}^{2}$ for the stress and taking into 
account the values of $A$ and $\beta$ given by Mogi we can write [19] in the following way without making large error:

$$
\log n(t)=\log \left(A N_{o}\right)+\beta \sigma_{o} \log e+\beta \tau t / \log e .
$$

The last relation derived on the basis of theoretical considerations and expiremental results, indicates that, if the applied stress on heterogeneous brittle material varies linearly with time, the logarithm of the time distribution of shocks must vary also linearly with time under certain conditions. This means that, if the water loading influenced the release of the foreshockes, a linear relation must exist between the water level and the logarithm of $n(t)$ after December 4 .

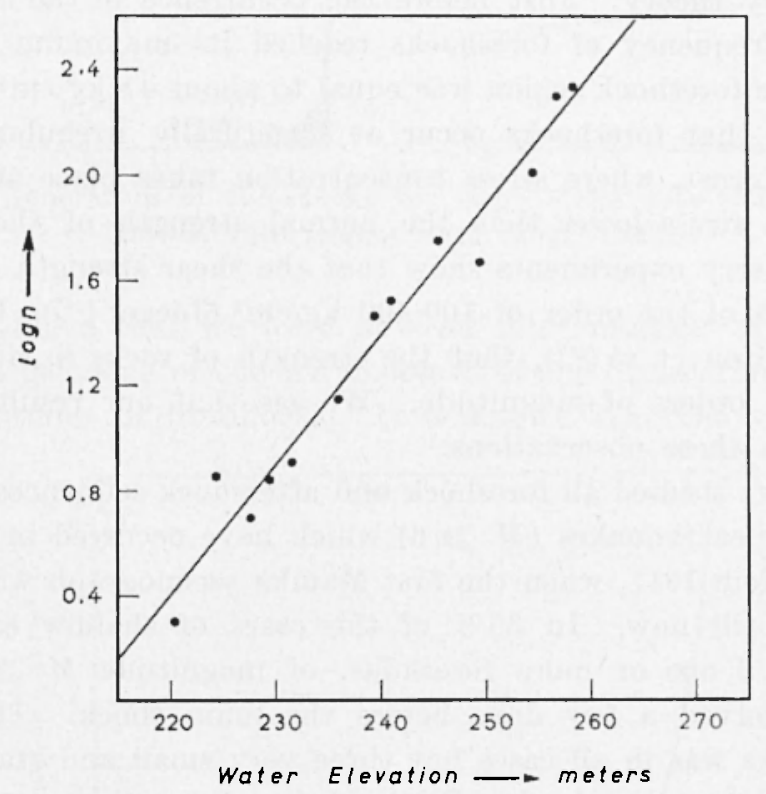

Fig. 10 - Relation between frequency of foreshocks and water elevation in the artificial lake.

Both quantities are known and $\log n(t)$ is plotted versus water level in Figure 10. The plot shows a very strong linear correlation. A value equal to 0.98 has been calculated for the correlation ratio.

Comparing equation [5] with [20] we find:

and

$$
\beta r \log e=0.03 \text {, }
$$

$$
\log A+\log N_{0}+\sigma_{\circ} \beta \log e=-0.30 \text {. }
$$


Since $r$ is equal to $0.067 \mathrm{~kg} / \mathrm{cm}^{2} /$ day we find from the first of these relations that $\beta-1.10 \mathrm{~cm}^{2} / \mathrm{kg}$. Using this value of $\beta$ and the the value of $A$ determined by $M$ ogi and $N_{0}-740$, we find from the second equation that $\sigma_{o}=37 \mathrm{~kg} / \mathrm{cm}^{2}$. Since the stress exerted by the water on December 4 had been about $8 \mathrm{~kg} / \mathrm{cm}^{2}$, the stress in the foreshock region due to tertonic forces was of the order of $29 \mathrm{~kg} / \mathrm{cm}^{2}$ at the time of damming (end of July). After the end of July the rate of stress increased, due to inpounding of the lake, but shocks scaresly occurred till December 4 , when the stress reached the value $37 \mathrm{~kg} / \mathrm{cm}^{2}$. After that time the rate of stress was constant and equal to $0.067 \mathrm{~kg} / \mathrm{cm}^{2} /$ day and the number of shocks increased according to [20], as it has been predicted by theory. Just before the occurrence of the main shock, when the frequency of foreshocks reached its maximum value, the stress in the foreshock region was equal to about $41 \mathrm{~kg} / \mathrm{cm}^{2}$. It must be noticed, that foreshocks occur at stracturally irregular points in the earth's crust, where stress c.ncentration takes place and fracture occurs at a stress lower than the normal strength of the material.

I aboratory experiments show that the shear strength of the crustal rocks is of the order of $100-400 \mathrm{~kg} / \mathrm{cm}^{2}$ (Jaeger $\left({ }^{2-1}\right)$ ). It has been shown (Chilton et al $\left.{ }^{(25)}\right)$, that the strength of rocks in situ is reduced up to 2 orders of magnitude. We see that our results are consistent with these observations.

We have studied all foreshock and aftershock sequences (60 cases) of the large earthquakes ( $I \geqslant 6$ ) which have occurred in the region of Greece from 1911, when the first Mainka seismograph was installed in Athens, till now. In $35 \%$ of the cases of shallow earthquakes with $M \geqslant 6$ one or more foreshoks, of magnitude $M \geqslant 3.5$, were usually observed a few days before the main shock. The number of foreshocks was in all cases but three very small and started a few days before the main shock. We have found no other cases in which the recorded foreshocks were so numerous as in the Cremasta lake. This probably is partly cue to the fact that before August 1965 only the Athens station existed in the area of Greece (except one Wi chert seismograph in Patras since 1963) and before 1957 even this station was equippeil with low magnification instruments. However, the number of recorded foreshocks from foci close to Athens or close to the other stations is very small and these shocks follow the general rule to start a few days before the main shock, even after the installation of the high magnification instruments. This is explained easily now. The frequency of foreshocks is small because the rate of in- 
crease of stress due to tectonic forces is small. The foreshock sequence of the Cremasta lake earthquake is an exception because the normal rate of stress increased remarkably due to the water loading. The frequency of foreshocks for large and small stress rate is shown after Mogi $\left({ }^{15}\right)$ in Figure 11. However, the foreshock sequences need further investigation by using records of very small shorks because it can eventually contribute to the problem of earthquake prediction.
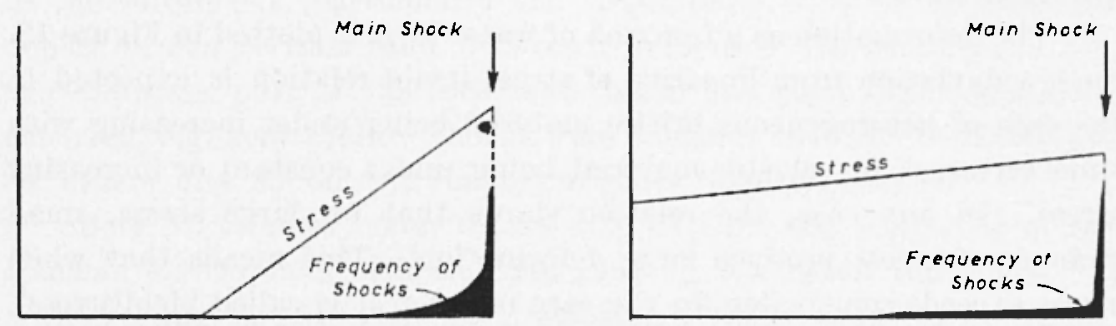

Fig. 11 - Generation of foreshocks for large stress rate (left.) and small stress rate (right) after Mogi, 1962.

We believe that we have now an interpretation of the exceptionally large value of the parameter $b^{\prime}$ of the cumulative function of the magnitudes of foreshocks. It is known that the value of this

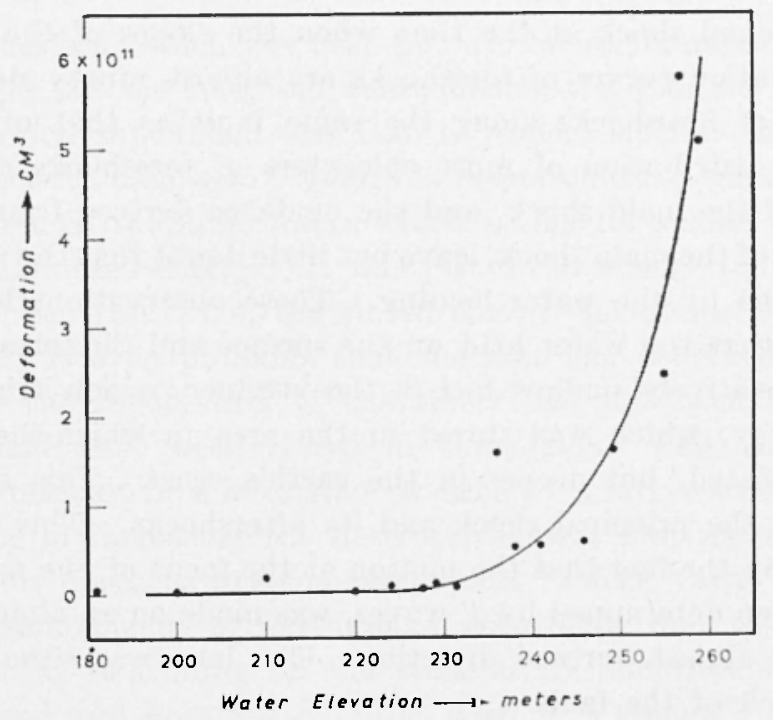

Fig. 12 - Relation between pressure exerted by the water on the bottom of the lake and deformation caused in the foreshock region. 
parameter increases not only with the heterogeneity of the material but also with the asymmotry of the applied stress. The heterogeneity of the material and asymmctry of the stress in the present case is due to the shallowness of the foreshock region and the almost vertical direction of the force due to water loading, respectively. The value calculated for the focal depth of the main shock and the smaller value of $b^{\prime}$ found for aftershocks indicate that much energy was stored in a deeper region.

The deformation as a function of water level is plotted in Figure 12. Such a deviation from linearity of stress-strain relation is expected in the case of heterogeneous brittle material being under increasing with time stress or for plastic material being under constant or increasing stress. In any case, the relation shows that for large stress, small changes of stress produce large deformation. This means that when stress exceeds some value (in the case of creep it is called yield stress), the deformation depends much on the rate of stress change.

\section{TRIGGERING OF THE MAIN SHOCK.}

We have till now shown that a strong correlation exists between the water loading and the occurrence of foreshocks. The occurrence of the principal shock at the time when the slopes of the frequency and deformation curves of foreshocks are ahnost ninety degrees, the generation of foreshocks along the same fault as that of the main shock, the distribution of most epicenters of foreshocks around the epicenter of the main shock, and the evidence derived from the focal mechanism of the main shock, leave but little doubt that the main shock was triggered by the water loading. These observations lead to the conclusion that the water load on the surface and the foreshocks ge:erated at relatively shallow foci in the strained region triggered the elastic energy, which was stored in the area in which the foreshock foci were seated, but deeper in the earth's crust. This energy was released by the principal shock and its aftershocks. This is strongly supporter by the fact that the motion at the focus of the main shock, as it has been determined by $P$ waves, was made on an almost vertical fault in an almost vertical direction. The lake was situated in the sinking block of the fault.

The brittleness of the material decreases with the depth and rather creep deformation predominates to some degree at the depth of the 
focus of the main shock. Since the stress-strain relation is a concare upward curve it follows that the tectonic forces acting in that depth increased the stress beyond the yield stress of the material and it was then easy for a minor force of the order of $10^{\circ}$ tons exerted vertically, with a relative large rate of increase on the one side of an almost vertical fault, to bring the material to the fracture point, e.g. to trigger the main shock. It is even possible that the foci of some of the foreshocks, particularly the larger ones, were at intermediate depths in the vertical fault between the focus of the main shock and the shallower part of the foreshock region and some chain triggering occurred, e.g. very shallow shocks were triggered first and these triggered others and so on till the main shock finally occurred.

Berg ( ${ }^{5}$ ) assumes creep fracture to explain the triggering of the Alaskan Earthquake of March 28, 1964 by low ocean tide loads. It is interesting to note that Berg assumed a value equal to $30 \mathrm{~kg} / \mathrm{cm}^{2}$ for the stress, which is equal to the value we have obtained by direct comparison of the observations with laboratory results on the assumption that the artificial lake influenced the generation of earthquakes.

There is no evidence for any correlation between the waterload and aftershocks. As we have already pointed out the Cremasta aftershock sequence has the characteristics of a normal aftershock sequence.

The question, which has been put by the inhabitans of the region is whether or not the lake, and consequently the Electric Power Corporation which inpounded the lake is responsible for the casualties and the property damages. Nature is responsible for the destruction. Nature produces the large forces which acting for a long time in the region accumulated energy. It was just a coincidence that the filling of the lake occurred when the stored energy was almost ready to be released. It is even probable that the lake has benefited the inhabitans. If the inpounding of the rivers had not been made more energy would have been stored in the region. This energy could have been released in a later time at once by a larger shock with the consequence of increasing the destructiveness. This means that the lake probably operated to some extent as a "safety valve".

The phenomenon of earthquake occurrence due to anomalous crustal loading depending on the stress-strain condition of the area is not general and does not manifest itself in a standard form. The case, for example, of the Marathon lake, which was observed by Galanopoulos, differs from that of Cremasta by the fact that in the 
resrion of the former no much energy was concentrated and a swarm of only small shorks occurred. In other cases of artificial lake inpounding no shocks were observed. Richter ${ }^{(26)}$ describing the phenomenon observed in the lake Mead pointed out that "The tectonic equilibrium was sufficiently delicate to be desturbed by this comparatively minor additional loal". Although in a small number of cases such phenomena were observed, nevertheless this possibility must be taken seriously in to account in constructing new dams.

\section{SUMMIARY AND CONCLUSION.}

Empirical relations which describe the laws of magnitude and time distribution as well as of the strain release have been derived not only for the aftershocks but also for the foreshocks of the Cremasta lake earthquake, which occurred on February 5, 1966. The space distribution of these shocks has been also studied.

The distribution of epicenters indicates that the main fault responsible for these earthquakes strikes $\mathrm{N} 114 \mathrm{~W}$. This is in agreement with fault plane solution found for the main shock. The fault is dipping almost vertically and the direction of motion on the fault makes a large slip angle. The lake is on the sinking block of the fault. The focal depth has been estimated by several methods. It was found that the depth of the main shock is of the order of $20 \mathrm{~km}$. There are several evidence that the foreshocks are very shallow.

The value of the parameter $b^{\prime}$ of the cumulative distribution of magnitude of aftershocks was found equal to 1.12 , while the value of the same parameter for foreshocks was found equal to 1.41. This is in striking contrast with the results of previous investigations according to which $b^{\prime}$ is much smaller for foreshocks than for aftershocks. This is attributed to the heterogeneity of the material of the foreshock region due to its shallowness and to the asymmetry of the stress distribution owing to additional force exerted by the waterloading of the Cremasta artificial lake.

Deformation as a function of time has been plotted for foreshocks and aftershocks. Assuming that the witter loading of the lake influenced the generation of foreshocks we should expect an upward concave curve between deformation and water level. Plot of deformation versus water level shows qualitatively the expected result. This curve shows why for stress beyond some value the rate of stress 
is of decisive importance for strain release and therefore explains the influence of the waterloading on the generation of foreshocks. The compressional and "shear" phases are not clearly shown in the deformation characteristics of aftershocks. However, these aftershocks have all the other properties of a normal aftershock sequence. The magnitude $M_{1}$ of the maximum normal aftershock is that predicted by the formula $M_{1}=1.07+0,71 M$, where $M$ is the magnitude of the main shcok.

$\Lambda$ large late aftershock occurred about nine months after the main shock. This earthquake was followed by secondary aftershocks. The space distribution of these late aftershocks verifies our previous conclusion, that the aftershock zone of the late aftershocks is only partly included in the aftershock volume of the main aftershock sequence and that the large late aftershock is triggered by the shocks of the main sequence.

The time distribution of foreshocks is expressed by the relation $\log n--0.30+0.03 t$ and the frequency function of the time between successive foreshocks by $n(\tau)=357^{-0.72}$. It is show $n$, on the basis of experimental and theoretical results, that if the wat. $r$ load of the artificial lake had influenced the generation of foreshocks, a linear relation must have existed between the pressure due to water and $n(t)$. Frequency of foreshocks versus water level has been plotted. A very strong linear correlation has been found between these two quantities. By comparison of theoretical and experimental results, with observational ones it was found that the stress before the inpounding of the rivers was of the order of $30 \mathrm{~kg} / \mathrm{cm}^{2}$ in the foreshock period. This value is of the order of the expected shear strength of rocks in their physical environment (in situ).

The time distribution of the aftershocks is expressed by $n(t)=$ $134 t^{-0.78}$ and the frequency function of the time between successive aftershocks by $n(t)=257 t^{-0.81}$.

\section{ACKNOWLEDGMENTS.}

The research reporte 1 in this document has been sponsored in whole by the Air Force Office of Scientific Research under Contract AF 61(052)-803 through the European Office of Aerospace Research (OAR) United States $A$ ir Force, as part of the Advanced Research Projects Agency's Project Vela-Uniform. The authors express their 
sincere appreciation to Dr. A. G. Galanopoulos, Dr. D. S. Carder and Dr. K. MIogi for critical reading of the manuscript and much helpful discussion.

\section{REFERENCES}

(1) CARder D. S., Seismic Investigations in the Boulder Dam Area, 1940. 19.4, and the Influence of Reservoir Loading on Local Earthquake Activity. "Bull. Seism. Soc. Am.", 35, pp. 175-192, (1945).

(') Guma s. K., RAM G. and RAo G. V., Trigger Oauses in Earth Wovements. "Publ. Bur. Cent. Seism. Intern., Trav. Sc.", Ser. A. Fasc. 19, pp. 345-355 (1956).

$\left(^{3}\right)$ McGixis I. D., Earthquakes and Crustal Movement as Related to Water Load in the Mississipi Valley Region. "Illinois State Geol. Survey", Circular 344, Urbana (1963).

(") Matuzawa 'T., Study of Earthquakes, "Uno Shoten", Tokyo, (1964).

(5) BERG E., Triggering of the Alaskan Earthquake of March 28, 1964 and Major Aftershocks by Low Tide Loads. "Nature" (In Press, 1966).

(') Evans M. D., Man-Made Earthquakes in Denver. "Geotimes", 11-18, May-June (1966).

(7) Calor P., Osservazioni sismiche e clinografiche presso grandi dighe di sbarramento. "Annali di Geofisica" VI, 3, (1953).

(8) CaLor P., La geodinamica al servizio delle grandi dighe. "Annali di Geofsica $»$ XVI, 1, (1965).

(') Caror P., L'evento del Vajont nei suoi Aspetti Geodinamici. "Annali li Geofisica”XIX, 1, (1966).

(10) Galanopoulos A., The Influence of the Fluctuation of Marathon Lake Elevation on Local Earthquake Activity in the Attica Basin Area." Annales Geologiques des Pays Helleniques", 18, pp. 281-306, (1966).

(11) Ben-MenaheM A. and BAtiI M., A Method for Determination of Epicenters of near Eartquakes. "Geof. Pura e Applicata" 46, II, pp. 37.46 (1960).

(12) Romsey C. F., An Investigation of the relationship between magnitude scales for small shocks. "Proc. Vesiac Conf. on Seismic Events Magnitude Determination", pp. 83.92, (1964).

(13) B\&TI .I. and DUda S., Earthquake Volume, Fault Plane Area, Seismic Energy, Strain Deformation and Related Quantities. "Annali di Geofisica ", 17, 3, (1964).

( ${ }^{\text {i. }) ~ P a p a z a c h o s ~ B ., ~ D e l i b a s i s ~ N ., ~ L i a p i s ~ N ., ~ M o u m o u l i d i s ~ G ., ~ a n d ~}$ Purcaru G., Foreshock and Aftershock Sequences of Some Large Earthquakes in the Region of Greece. "Annali di Geofisica" XX, 1, (1967). 
(15) Mogr K., On the Time Distribution of Aftershocks Accompanying the Recent Major Earthquakes in and near Japan. "Bull. Earthq. Res. Inst." 40. pp. 107-124, (1962a).

(18) Mogr K., Study of Elastic shocks caused by the Fracture of IIterogeneous Materials and its Relations of Earthquake Phenomena. "Bull. Earthq. Res. Inst.", 40, pp. 125-174, (1962b).

(17) UTsu T., A Stalistical Study of the Occurrence of Aflershocks. "Geoph. Magazine ". 38, pp. 521-605, (1961).

$\left({ }^{18}\right)$ Gutenberg B. and Ricirter C., Seismicity of the Earth and Associated Phenomena. "Princeton University Press" (1954).

(19) Karnik V., Seismicity of Europe. "Progress Report IY", 1-11 (1964).

${ }^{(20)}$ Galanopoulos A., Evidence for the Seat of the Strain-Producing Forces. "Annali di Geofisica", 18, pp. 399-409, (1965).

${ }^{(21)}$ Party for Seismographic Observation of Matsushiro Earthquakes and Seis. mometrical Section. Matsushiro Earthquakes Observed with a Temporary Seismographic Network. Part. 1. "Bull. Earthq. Res. Inst.", 40. pp. 309-333 (1966).

${ }^{(22)}$ Suyemro S., Difference between Aftershocks and Foreshocks in the Relationship of Magnitude to Frequency of Occurrence for the Great Chilean Earthquake of 1960, "Bull. Seism. Soc. Am.", 56, pp. 185-200, (1966).

(23) BeniofF H., Earthquake and Rock Creep. Part 1, "Bull. Seism. Soc. Am.", 41, pp. 31.62 (1951).

(21) JAEger J. C., Elasticily, Fracture and Flow. "John Wiley and son, Inc.", New. York (1964).

${ }^{(25)}$ Cintoton F., Eisien .J. D. and Heubacir II. G., Dynamic of Spalling of the Earth's Surface Caused by Underground Nuclear Erplosions. Abstract "Trans. Am. Geph. Union", 46, 539 (1965).

${ }^{(26)}$ Rictuer C., Elementary Seismology. "Freeman Co.", San Francisco, 1958. 